\title{
Exposure to polychlorinated biphenyl (PCB) congeners measured shortly after giving birth and subsequent risk of maternal breast cancer before age 50
}

\author{
Barbara A. Cohn • Mary Beth Terry • \\ Marj Plumb • Piera M. Cirillo
}

Received: 24 July 2012/ Accepted: 12 September 2012

(C) The Author(s) 2012. This article is published with open access at Springerlink.com

\begin{abstract}
Discrete windows of susceptibility to toxicants have been identified for the breast, including in utero, puberty, pregnancy, and postpartum. We tested the hypothesis that polychlorinated biphenyls (PCBs) measured during the early postpartum predict increased risk of maternal breast cancer diagnosed before age 50 . We analyzed archived early postpartum serum samples collected from 1959 to 1967, an average of 17 years before diagnosis (mean diagnosis age 43 years) for 16 PCB congeners in a nested case-control study in the Child Health and Development Studies cohort $(N=112$ cases matched to controls on birth year). We used conditional logistic regression to adjust for lipids, race, year, lactation, and body mass. We observed strong breast cancer associations with three congeners. PCB 167 was associated with a lower risk (odds ratio $(\mathrm{OR}), 75$ th vs. 25 th percentile $=0.2,95 \%$ confidence interval $(95 \% \mathrm{CI}) 0.1,0.8)$ as was PCB 187 (OR, 75 th vs. 25 th percentile $=0.4,95 \%$ CI $0.1,1.1$ ). In contrast, PCB 203 was associated with a sixfold increased risk $(\mathrm{OR}, 75$ th vs. 25 th percentile $=6.3,95 \%$ CI 1.9, 21.7) .
\end{abstract}

B. A. Cohn $(\bowtie) \cdot$ P. M. Cirillo

Child Health and Development Studies, Public Health Institute, 1683 Shattuck Avenue, Ste. B, Berkeley, CA 94709, USA

e-mail: bcohn@chdstudies.org

M. B. Terry

Department of Epidemiology, Mailman School

of Public Health of Columbia University, New York, NY, USA

M. B. Terry

Herbert Irving Comprehensive Cancer Center, Columbia

University Medical Center, New York, NY, USA

M. Plumb

Plumbline Coaching and Consulting, Inc., 2759 Park Street,

Berkeley, CA 94702, USA
The net association of PCB exposure, estimated by a posthoc score, was nearly a threefold increase in risk (OR, 75th vs. 25 th percentile $=2.8,95 \%$ CI 1.1, 7.1) among women with a higher proportion of PCB 203 in relation to the sum of PCBs 167 and 187. Postpartum PCB exposure likely also represents pregnancy exposure, and may predict increased risk for early breast cancer depending on the mixture that represents internal dose. It remains unclear whether individual differences in exposure, response to exposure, or both explain risk patterns observed.

Keywords PCBs - Polychlorinated biphenyls - Breast cancer · Pregnancy $\cdot$ Postpartum · Prospective · Human

\author{
Abbreviations \\ OR Odds ratio \\ PCB(s) Polychlorinated biphenyl(s) \\ $95 \%$ CI 95 percent confidence interval
}

\section{Introduction}

Discrete windows of susceptibility to toxicants have been identified for the breast, including in utero, during puberty, and during pregnancy and postpartum [1-4]. Human studies of breast cancer have not been able to assess the effects of measured exposure to environmental chemicals during windows of susceptibility for the breast $[2,5]$. The existing literature on polychlorinated biphenyls (PCBs) and breast cancer typically has focused primarily on postmenopausal breast cancer [6-8]. In addition, exposure in prior studies was largely measured in middle age or at time of diagnosis, was variable on how PCBs were classified and 
whether individual congeners were considered, and was based on samples obtained after PCB use was regulated [68 ]. The literature on the pesticide DDT and breast cancer is subject to similar limitations [9].

Findings on the relation of PCBs measured in middle age to breast cancer are complex and have been reviewed previously in detail (see Table 3, pp. 2872-2876 in Brody et al. [8]). Briefly, some studies reported positive associations with individual congeners, others reported no associations for total PCBs or any individual congeners, and others reported negative associations with some tumor types. The most consistent, positive findings were reported where interaction between exposure and CYP1A1 gene polymorphisms could be considered. Three studies found higher PCB exposures with postmenopausal breast cancer in combination with the CYP1A1 polymorphism, M2 type [10-12] and another reported this association with premenopausal breast cancer [13].

The present prospective study adds a unique perspective by testing the hypothesis that exposure to PCBs, measured during the early postpartum, is associated with increased risk of early breast cancer. Because of the long half-life of PCBs [14], early postpartum levels also reflect exposure during pregnancy [15] and possibly during childhood and adolescence. To our knowledge, this is the first study to report on breast cancer associations in relation to measured PCBs levels during critical periods of vulnerability for the breast.

\section{Materials and methods}

\section{Subjects}

Subjects were participants in the Child Health and Development Studies (CHDS), residents of the Oakland, California area and members of the Kaiser Permanente Health Plan who sought obstetric care between 1959 and 1967 [16]. Subjects voluntarily participated in the CHDS, giving an oral informed consent for an in-person interview, collection of blood specimens at several points in pregnancy and the early postpartum, and permission for medical record access. This study was reviewed and approved by The Institutional Review Board of the Public Health Institute and we have complied with all federal guidelines governing use of human participants.

Breast cancer cases were identified by linkage to the California Cancer Registry, and the California Vital Status Records [17]. All names for each CHDS subject are submitted for cancer linkages using fixed (i.e. birth date, sex, race, and name) and changeable (i.e. address and patient record number) identifiers. A rigorous protocol is used to verify cases, comparing fixed versus changeable identifiers by manual review. The California Cancer Registry is reported to be $>99 \%$ complete after a lag time of about 2 years [18].

Cases were defined as women with incident invasive or non-invasive breast cancer diagnosed before age 50, or deaths due to breast cancer before age 50, obtained from linkage conducted in early 1998 . There were 133 cases who met study criteria. All members of the CHDS cohort are additionally linked to the California Department of Motor Vehicles (DMV) files on a regular basis to determine residence history allowing us to assess their control status and to update any name changes. All names registered with the DMV are used in establishing a match. Simultaneous linkage of multiple family members enhances matching. The regular DMV matching provides a history of location for each subject which is used to determine the population at risk for cancer, corresponding with geographic surveillance by California's cancer registries. Subjects who cannot be located are considered lost to follow-up at the date of their last definitive classification as a California resident. One control, matched exactly on birth year, was selected at random for each case from those who were under cancer surveillance and known to be free of breast cancer at the age of diagnosis for the matching case. The median time to diagnosis for cases was 17 years. The mean age at diagnosis was 43 years.

\section{Serum assays}

Exposure to PCBs was measured by assays of serum samples drawn during the early postpartum period, within 1-3 days of delivery. Postpartum samples were used to conserve valuable archived serum samples drawn in each trimester for future studies where timed samples are essential. PCBs have a long half-life and prior work has established stability of organochlorine levels assayed across all trimesters of pregnancy and the early postpartum [15]. For this reason, postpartum levels of PCBs may accurately rank women on their pregnancy exposure, covering two potential vulnerable periods of susceptibility of the breast to toxicants.

PCBs were assayed in the laboratory of Dr. Mary Wolff [19] using modifications of methods developed previously by Brock et al. [20]. Briefly, a polar extraction of serum lipids is followed by a column chromatographic clean-up and enrichment step, with analysis by gas chromatography with electron capture detection. Limits of detection were approximately $0.07 \mathrm{ng} / \mathrm{mL}$ for individual compounds based on three times the standard deviation of the levels found in the lowest quality control plasma pool [21]. When the serum pool and blanks were considered together [22], the limit of detection was $0.01-0.1 \mathrm{ng} / \mathrm{mL}$; the instrumental limit of detection based on a peak-to-noise ratio of 
3 was $0.01-0.03 \mathrm{ng} / \mathrm{mL}$ for tetra- through hepta-chlorobiphenyls, using 1-1.5 mL plasma. As described previously [23], we used all observed positive values of PCBs in analyses, even those reported to be below the limit of detection.

We were able to assay archived serum samples for the PCB congeners which are shown in Table 1. These congeners include those most commonly reported in prior studies, comprised the congeners with highest concentrations, or grouped by potential biological activity as previously recommended [24]. We randomly assigned the order of samples within and across batches and analyzed casecontrol pairs in the same batches to minimize differences due to laboratory drift. The laboratory was blind as to case or control status of the samples. Intra-batch coefficients of variation ranged from $5 \%$ for PCB 180 to $18 \%$ for PCB 101. Total cholesterol and total triglycerides were measured enzymatically on the Hitachi 911 analyzer (Roche Diagnostics, Indianapolis, IN) in a lab certified by the Centers for Disease Control and Prevention and the
National Heart Lung and Blood Institute Lipid Standardization Program.

\section{Statistical analysis}

This report is based on 112 case-control pairs, matched on year of birth, after excluding 2 pairs with insufficient serum for lipid assays, 2 pairs with missing data on body mass index, and 17 pairs where one or more member of the pair was missing information on PCB 167, which was not quantified in one of the assay batches. In a sensitivity analysis, we imputed missing PCB 167 by matching on case status and date of blood draw and assigning a PCB value for the missing individual based on a random pick of all matches. Results were similar (associations were of a similar magnitude with overlapping $95 \%$ confidence intervals and all associations remained statistically significant, defined as $p<0.05$ ) whether or not the individuals with imputed values were included. We present findings only for individuals with non-missing data on all study

Table 1 Distribution of PCBs in breast cancer controls and cases

\begin{tabular}{|c|c|c|c|c|c|c|c|c|c|c|}
\hline \multirow[t]{3}{*}{ Classification [24] } & \multirow[t]{3}{*}{ PCB } & \multirow{2}{*}{\multicolumn{3}{|c|}{$\frac{\text { Controls }(N=117)}{\text { Percentile }(\mathrm{mmol} / \mathrm{l})}$}} & \multirow{2}{*}{\multicolumn{3}{|c|}{$\frac{\text { Cases }(N=123)}{\text { Percentile }(\mathrm{mmol} / \mathrm{l})}$}} & \multirow{2}{*}{\multicolumn{2}{|c|}{$\begin{array}{l}\text { Difference within } \\
\text { matched pairs } \\
\text { (case-control, } N=112 \text { ) }\end{array}$}} & \multirow{3}{*}{ Percent $>$ LOD } \\
\hline & & & & & & & & & & \\
\hline & & 25 th & 50 th & 75 th & 25 th & 50 th & 75th & Mean $(\mathrm{mmol} / \mathrm{l})$ & $p$ value & \\
\hline \multirow[t]{3}{*}{ Estrogenic } & 101 & 0.37 & 0.74 & 1.07 & 0.34 & 0.55 & 0.92 & -0.06 & 0.19 & 89 \\
\hline & 187 & 0.38 & 0.48 & 0.66 & 0.38 & 0.48 & 0.63 & -0.07 & 0.30 & 100 \\
\hline & 201 & 0.09 & 0.23 & 0.33 & 0.14 & 0.23 & 0.30 & -0.01 & 0.71 & 71 \\
\hline \multicolumn{11}{|l|}{ Anti-estrogenic } \\
\hline \multirow{6}{*}{$\begin{array}{l}\text { A. Non-ortho, mono-ortho, } \\
\text { dioxin-like }\end{array}$} & 66 & 0.89 & 1.34 & 1.78 & 0.96 & 1.47 & 1.95 & 0.10 & 0.17 & 99 \\
\hline & 74 & 0.62 & 0.89 & 1.23 & 0.62 & 0.86 & 1.27 & 0.01 & 0.54 & 95 \\
\hline & 105 & 0.25 & 0.40 & 0.64 & 0.25 & 0.43 & 0.61 & -0.01 & 0.92 & 81 \\
\hline & 118 & 1.19 & 1.62 & 2.02 & 1.19 & 1.53 & 2.11 & -0.03 & 0.94 & 100 \\
\hline & 156 & 0.11 & 0.28 & 0.42 & 0.11 & 0.28 & 0.39 & -0.03 & 0.68 & 64 \\
\hline & 167 & 0.08 & 0.19 & 0.30 & 0.08 & 0.14 & 0.25 & -0.03 & 0.12 & 49 \\
\hline \multirow{2}{*}{$\begin{array}{l}\text { B. Di-ortho, limited } \\
\text { dioxin activity }\end{array}$} & 138 & 1.58 & 2.05 & 2.55 & 1.50 & 2.02 & 2.77 & -0.09 & 0.56 & 100 \\
\hline & 170 & 0.30 & 0.46 & 0.66 & 0.35 & 0.48 & 0.63 & -0.01 & 0.74 & 97 \\
\hline \multirow{6}{*}{$\begin{array}{l}\text { Phenobarbital, CYP1A, } \\
\text { and CYP2B inducers }\end{array}$} & 99 & 0.28 & 0.58 & 0.80 & 0.25 & 0.52 & 0.86 & -0.04 & 0.30 & 83 \\
\hline & 153 & 1.88 & 2.38 & 3.08 & 1.86 & 2.43 & 3.08 & -0.08 & 0.40 & 100 \\
\hline & 180 & 0.89 & 1.21 & 1.54 & 0.94 & 1.21 & 1.57 & 0.01 & 0.63 & 100 \\
\hline & 183 & 0.13 & 0.23 & 0.35 & 0.10 & 0.23 & 0.33 & -0.03 & 0.32 & 66 \\
\hline & 203 & 0.21 & 0.30 & 0.42 & 0.23 & 0.35 & 0.47 & 0.02 & 0.20 & 90 \\
\hline & $203 / 167+187$ & 0.34 & 0.43 & 0.52 & 0.38 & 0.50 & 0.63 & 0.09 & NA & NA \\
\hline
\end{tabular}

Variable number of subjects in each group is due to missing data on one or more of the PCB congeners shown. The PCB score (PCB 203/(PCB 187 + PCB 167)) was based on the best fitting model as described in the text, and is provided to describe the distribution of the mixture of significant PCB predictors. $p$ values are not presented for the PCB score because the score was created after analysis, as described in text. $p$ values shown are for Wilcoxon Signed Rank Test of differences (case-control) within age-matched case-control pairs

$L O D$ limit of detection 
variables, as this is a conservative choice based on observed values.

We performed data analysis using age-matched conditional logistic regression as in our prior study of DDT and breast cancer in this same population [25]. We began with a full model, entering all PCBs classified by Wolff et al. [24]. as potentially relevant to human health: Group 1 consisted of congeners detected in the CHDS serum samples that were considered to be potentially estrogenic and persistent (PCB 101,187, 201). Group 2 consisted of congeners detected in the CHDS serum samples that were considered to be potentially antiestrogenic, immunotoxic, dioxin-like: Group 2A which are non-ortho or mono-ortho in their structure (PCB 66, 74,105,118,156,167) and Group 2B which are di-ortho and have more limited dioxin-like activity (PCB 138 and 170). Group 3 consisted of phenobarbital, CYP1A and CYP2B inducers (PCB 99, 153,180, $183,203)$. Congeners that had individual $p>0.20$ were tested for removal as a group, based on a likelihood ratio test ( $p<0.15$ as the criterion). At the next step, we used a more stringent criterion, eliminating remaining PCB terms with individual significance probabilities $>0.05$. In addition to using the likelihood ratio test to test the hypothesis that the coefficients for these terms were each 0 using the criterion, $p<0.15$, we also examined the sign and size of coefficients of remaining predictors before and after elimination to rule out major confounding by the eliminated predictors. Our goal was to identify the minimal number of PCBs that predicted risk. Once the best PCB model was identified, we examined whether further adjustment for blood lipids (total cholesterol, total triglycerides), parity, year of blood draw, body mass index (lower tertile, upper tertile vs. middle tertile as the reference category) and breast feeding following the current pregnancy altered PCB associations with breast cancer.

To describe the net effect of PCB exposure on breast cancer, we constructed a post-hoc score that consisted of the ratio of the sum of PCB congener(s) associated with higher risk of breast cancer to the sum PCB congeners associated with lower risk as in a previous report on health effects of PCB exposure in this population [26]. We then examined the variation in the post-hoc score and described its association with breast cancer in this population.

\section{Results}

Table 1 shows the distribution of PCB congeners and a post-hoc PCB score based on the final model shown in Table 2. In this study population, PCB congener concentrations and the distribution of the PCB score were highly variable. The comparisons between cases and controls in Table 1 show no remarkable, statistically significant
Table 2 Associations of individual PCB congeners with breast cancer diagnosed before 50 years of age

\begin{tabular}{|c|c|c|c|c|c|}
\hline \multirow{2}{*}{$\begin{array}{l}\text { Classification } \\
{[24]}\end{array}$} & \multirow[t]{2}{*}{ PCB } & \multicolumn{2}{|c|}{ Model with all PCBs } & \multicolumn{2}{|l|}{ Final model } \\
\hline & & Coefficient & $p$ value & Coefficient & $p$ value \\
\hline \multirow[t]{3}{*}{ Estrogenic } & 101 & 0.39 & 0.41 & & \\
\hline & 187 & -4.18 & 0.03 & -2.07 & 0.02 \\
\hline & 201 & -2.70 & 0.23 & & \\
\hline \multicolumn{6}{|l|}{ Anti-estrogenic } \\
\hline \multirow{6}{*}{$\begin{array}{l}\text { A. Non- } \\
\text { ortho, mono- } \\
\text { ortho, dioxin- } \\
\text { like }\end{array}$} & 66 & 0.11 & 0.61 & & \\
\hline & 74 & 0.36 & 0.53 & & \\
\hline & 105 & 1.37 & 0.19 & & \\
\hline & 118 & -0.82 & 0.07 & & \\
\hline & 156 & -0.42 & 0.61 & & \\
\hline & 167 & -2.50 & 0.17 & -2.88 & 0.03 \\
\hline \multirow{2}{*}{$\begin{array}{l}\text { B. Di-ortho, } \\
\text { limited } \\
\text { dioxin } \\
\text { activity }\end{array}$} & 138 & 0.10 & 0.87 & & \\
\hline & 170 & -1.45 & 0.34 & & \\
\hline \multirow{5}{*}{$\begin{array}{l}\text { Phenobarbital, } \\
\text { CYP1A, and } \\
\text { CYP2B } \\
\text { inducers }\end{array}$} & 99 & -0.45 & 0.56 & & \\
\hline & 153 & 0.10 & 0.91 & & \\
\hline & 180 & 1.26 & 0.28 & & \\
\hline & 183 & 1.15 & 0.48 & & \\
\hline & 203 & 6.17 & 0.01 & 4.36 & 0.001 \\
\hline
\end{tabular}

In the column labeled, "Model with all PCBs", congeners were entered into a single model as the first step in model selection. Congeners PCB 203, 187, 167 118, and 105 were initially retained based on the criterion of $p<0.20$. PCB 118 and 105 were then removed either one at a time or together. They were deleted from the final model by applying the likelihood ratio test where $\chi^{2}=3.81,2 \mathrm{df}$, $p=0.15$ for the test to retain both PCB 105 and PCB 118 in the model. Both were tested for removal simultaneously because deleting either PCB 118 or PCB 105 alone greatly affected the size of coefficient for the other. There were $N=112$ age-matched case-control pairs for all models shown and all models tested. Coefficients are reported per $1 \mathrm{mmol} / \mathrm{l}$

associations between single PCB congeners and breast cancer risk, in the absence of control for other congeners. This observation suggests that confounding would play a role in any associations observed in multivariate models.

There were no associations between the sum of total PCBs or with PCB groups (groups shown in Table 1) and risk of breast cancer (data not shown). Table 2 shows results of multivariate conditional logistic regression models for individual PCB congeners. PCB 203 is the only congener with a consistent and statistically significant positive coefficient, indicating that it was associated with increased risk of breast cancer (Table 2, both models). In contrast, PCB 167 and PCB 187 were inversely associated with risk of breast cancer (Table 2, both models). To check for dose response, we also estimated associations for these PCBs by quartile shown in Table 3. Results were largely consistent with a monotonic trend for each congener. 
Table 3 Associations of PCB 167, 187, and 203 with breast cancer diagnosed before 50 years of age

\begin{tabular}{llll}
\hline PCB & Quartile & Odds ratio $(95 \% \mathrm{CI})$ & $p$ value for linear trend \\
\hline 167 & Q1 & 1.00 & $<0.04$ \\
& Q2 & $1.09(0.48,2.47)$ & \\
& Q3 & $0.70(0.27,1.78)$ & \\
& Q4 & $0.24^{* *}(0.07,0.79)$ & \\
187 & Q1 & 1.00 & $<0.02$ \\
& Q2 & $0.94(0.41,2.17)$ & \\
& Q3 & $0.92(0.36,2.38)$ & \\
& Q4 & $0.35^{*}(0.11,1.14)$ & \\
203 & Q1 & 1.00 & $<0.001$ \\
& Q2 & $1.21(0.46,3.18)$ & \\
& Q3 & $2.89^{* *}(0.98,8.55)$ & \\
& Q4 & $6.34^{\dagger}(1.85,21.73)$ &
\end{tabular}

Each of the three PCBs is coded as quartiles, based on the distribution in controls. Quartile 1 is the reference category and quartiles 2, 3, 4 are entered as dummy variables for each PCB shown. Associations shown are based on a single model where quartile terms for all PCBs are entered. $P$ value for trend is estimated from a linear model where all three PCBs are entered as continuous variables. $N=112$ casecontrol pairs

$C I$ confidence interval, $p$ significance probability

$* p \leq 0.10$

$* * p \leq 0.05$

${ }^{\dagger} p \leq 0.01$

Table 4 Estimated net effects of PCB exposure on risk of breast cancer before 50 years of age

\begin{tabular}{|c|c|c|}
\hline Level of adjustment & $\begin{array}{l}\text { Quartile of PCB } \\
\text { score }^{\mathrm{a}}\end{array}$ & $\begin{array}{l}\text { Odds ratio } \\
(95 \% \mathrm{CI})\end{array}$ \\
\hline \multirow[t]{4}{*}{ Unadjusted } & Q1 & 1.00 \\
\hline & Q2 & $1.26(0.53,3.00)$ \\
\hline & Q3 & $1.52(0.64,3.62)$ \\
\hline & Q4 & $3.01(1.34,6.78)$ \\
\hline \multirow{4}{*}{$\begin{array}{l}\text { Cholesterol and } \\
\text { triglycerides }\end{array}$} & Q1 & 1.00 \\
\hline & Q2 & $1.23(0.53,3.07)$ \\
\hline & Q3 & $1.53(0.64,3.68)$ \\
\hline & Q4 & $3.09(1.34,7.16)$ \\
\hline \multirow{4}{*}{$\begin{array}{l}\text { Cholesterol, triglycerides, } \\
\text { race, parity, lactation, } \\
\text { body mass index, } \\
\text { and year of blood } \\
\text { sampling }\end{array}$} & Q1 & 1.00 \\
\hline & Q2 & $1.36(0.53,3.52)$ \\
\hline & Q3 & $1.78(0.70,4.55)$ \\
\hline & Q4 & $2.81(1.11,7.09)$ \\
\hline
\end{tabular}

CI confidence interval

a A post-hoc PCB score was defined to describe the net effect of PCB exposure in this study sample (described in text). PCB 203 was associated with increased risk, while PCBs 167 and 187 were associated with decreased risk (see final model, Table 2). Therefore, the PCB score was defined as the proportion of PCB 203 relative to the sum of PCBs 167 and 187: PCB 203/(PCB $167+$ PCB 187). $N=112$ age-matched case-control pairs for all models shown
Based on the results in Tables 2 and 3, a PCB score was constructed as the ratio of PCB 203 (positively related to risk) to the sum of PCBs 167 and 187 (each negatively related to risk). The PCB score was highly variable in the cohort, ranging from $8 \%$ PCB 203 (compared to the sum of PCBs 187 and 167) to $131 \%$ PCB 203. Overall for cases and controls combined, the median of the 4th quartile (0.67) was 2.3 times higher than the median of the $1 \mathrm{st}$ quartile (0.30). Among controls, the median of the 4th quartile of the PCB score (0.61) was 2.5 times higher than the median of the 1 st quartile of the PCB score $(0.25)$. Among cases, the median of the 4 th quartile of the PCB score (0.71) was 2.2 times higher than the median of the $1 \mathrm{st}$ quartile of the PCB score (0.32).

Table 4 shows the net effect of exposure based on the proportion of PCB 203 compared to the sum of PCBs 167 and 187 . Women in the top $25 \%$ of the PCB score had nearly three times the risk of breast cancer as women in the bottom $25 \%$ of the PCB score. Adjustment for lipids or other breast cancer risk factors had little effect on this result (Table 4), nor did adjustment for the denominator of the PCB score or adjustment for $p, p^{\prime}$-DDT, $o, p^{\prime}$-DDT, and $p, p^{\prime}$-DDE (data not shown).

Figure 1 shows the actual distribution of the within-pair differences for the PCB score for cases versus controls in this study sample. In the majority of case-control pairs (62\%), the PCB score was higher among the woman who subsequently developed breast cancer. Pairs where the case had a higher PCB score also showed greater differences on the PCB score than pairs where the control had a higher score (seen in Fig. 1; compare the right side of the $Y$-axis (center axis) which shows pairs where cases within the pair had a higher PCB score to the left side of the $Y$-axis which shows pairs where controls had a higher PCB score). Figure 1 is consistent with the modeling results shown in Tables 2, 3 and 4.

\section{Discussion}

The net effect of PCB exposure in this study population was nearly a threefold increase in breast cancer risk among women who had a higher proportion of PCB 203 in relation to the sum of PCB 167 and PCB 187 (75th percentile vs. 25th percentile). These results are novel, but not inconsistent with the prior literature on PCBs and breast cancer.

Three comprehensive reviews concluded previously that human studies of PCBs and breast cancer, which measured exposure in midlife, had variable findings [6-8]. Most prior studies reported primarily on total PCBs, which are largely determined by the PCBs found in highest concentration in humans (PCB 153, PCB 138, PCB 118, and PCB 180). We too found no associations for total PCBs, high 


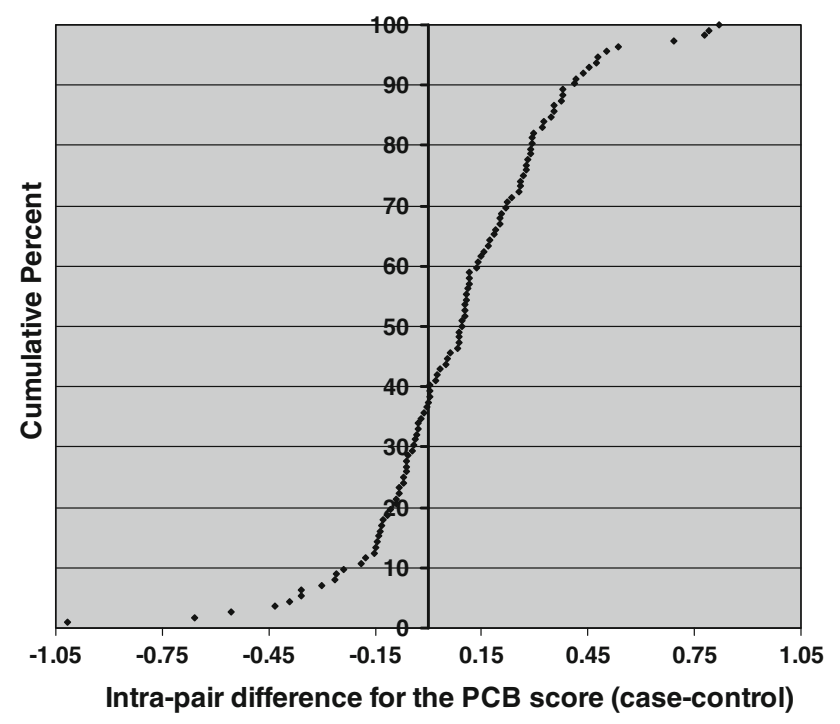

Fig. 1 Cumulative distribution of case-control differences for the PCB score $(N=112$ age-matched case control pairs). Each point represents one case-control pair. The points on the right side of the $y$ axis (center axis) are positive values that represent pairs where the woman who developed breast cancer had a higher PCB score postpartum than her matched control. In a majority of pairs (62\%), the woman who subsequently developed breast cancer had a higher PCB score. The differential for the PCB score was also greater for pairs where the case had a higher score than her matched control (compare points on the right of the $y$-axis to points on the left of the $y$ axis)

concentration PCBs or sums of PCBs in functional groupings previously proposed by Wolff et al. [24]. No prior studies reported on the independent contribution of the three lower concentration congeners that predicted breast cancer in this study.

It is notable that prior studies did not measure exposure in young women, during windows of susceptibility during early life, when the breast might be more susceptible to endocrine disruption, including in utero, puberty, pregnancy, or the postpartum [1-3]. Our ability to directly measure exposure during the early postpartum is a particular strength of this study. A recent meta-analysis of pregnancy-associated breast cancer outcomes found that women diagnosed with breast cancer in pregnancy, and particularly women diagnosed postpartum, had poorer survival [4], providing further evidence supporting the hypothesis that pregnancy and the postpartum period are vulnerable periods for the breast.

As PCBs are highly persistent, it is likely that postpartum levels also reflect pregnancy levels, as suggested by one longitudinal study that reported high correspondence between early postpartum levels and levels across all three trimesters of pregnancy [15]. As women were young at the time of blood collection, it is also possible that the early postpartum levels of PCBs reflect exposure even prior to pregnancy, possibly during puberty, as well. This might explain the strength of the association observed for PCB 203, a higher chlorinated compound, as compounds with this structure tend to have longer half-lives [14].

Other strengths of this study include prospective assessment of exposure an average of 17 years before diagnosis, simultaneous consideration of individual PCB congener effects, and the opportunity to observe a population during active exposure because blood samples were obtained before PCBs were restricted.

Our focus on breast cancer at a young age is an additional strength. Molecular studies strongly suggest that premenopausal breast cancer may not share the same features or risk factors as breast cancer diagnosed in middle age and older [27, 28]. Our findings could lead to better understanding about etiology, prevention, and treatment of early breast cancer, if the mechanisms for the associations we observed can be validated and investigated by experimental toxicology and molecular studies.

Our choice to estimate the net effect of exposure to observed PCB mixtures found in our study participants is an additional strength. While our approach will likely be improved upon as the methods for analyzing mixed exposures advances; here, we applied an empirical approach to describe more than individual congener associations. It is of interest that the protective associations for PCBs 187 and $167 \mathrm{did}$ not overcome the stronger, deleterious association observed for PCB 203. There are several speculative explanations for this finding, the first being that PCB 203 is a particularly strong risk factor, as evidenced by its point estimate. Alternatively, as the higher chlorinated PCBs are eliminated more slowly, it is possible that postpartum levels of PCB 203 more accurately reflect exposure even earlier in life, including accumulations in utero, childhood and during puberty, periods of susceptibility for the breast in addition to pregnancy and postpartum.

Limitations of our study include the possibility of unmeasured confounding by other exposures. In particular, we were unable to measure dioxin exposure or activity, raising the possibility that this or other unmeasured confounders could have masked or accounted for the associations we report here. However, as we observed dose response, unmeasured confounding would have to follow the same pattern, making this alternative explanation of our findings less likely. It is also possible that host factors that influence the metabolism or selective excretion of various PCB congeners underlie the associations we observed. We used early postpartum samples to save valuable timed serum samples during pregnancy for other studies in the cohort. However, prior studies conducted in serum samples of the same age found good correspondence of these persistent organochlorines across all trimesters and the early postpartum [15], suggesting that postpartum PCB levels 
may also reflect pregnancy exposures. Still our study cannot establish the age or developmental period when PCB exposure was acquired, other than establishing that exposure preceded the mean age of blood collection (age 26 years). Storage of serum samples is unlikely to have biased study results, as all samples were similarly stored. Randomization of samples within and between batches and inclusion of controls and cases in the same batches minimized inter- and intra-batch laboratory error.

Interpretation is limited by a lack of understanding about the potential mechanism for PCB associations observed. The direct association between PCB 203 and early breast cancer was sizable and significant. However, the mode of action for PCB 203, classified as a phenobarbital (PB) inducer [24], is unknown. A PubMed search for "PCB 203" returned no citations, compared to 589 citations for "PCB 153," for example. The Agency for Toxic Substances and Disease Registry report on the toxic effects of PCBs makes no specific mention of PCB 203 effects [29].

PCB 187 has been classified as potentially estrogenic [24], but it is unclear how postpartum or pregnancy exposure might be associated with a lower risk of breast cancer. This study provides little information regarding the validity of the classification of PCB 187 as estrogenic. In our previous report on the relation of prenatal PCB exposure to time to pregnancy in daughters in this same cohort [26], we found that a longer time to pregnancy in daughters was associated with prenatal exposure to PCB 187. The significant associations observed for breast cancer in mothers and time to pregnancy in daughters following prenatal exposure to PCB 187 deserves additional study, perhaps in experimental models or in vitro systems. It could be of interest to characterize PCB 187 effects in the case of low versus high endogenous levels of estrogen and during pregnancy and postpartum in particular.

We were unable to investigate gene/PCB interactions in this study. The absence of associations for some of the PCBs investigated might be explained by failure to identify susceptible sub-populations of women. Previously, associations were more consistently observed in sub-populations characterized by variant alleles for enzymes that metabolize PCBs (Cytochrome P4501A1 variants) [10-13]. We were also unable to characterize the receptor status of the breast tumors in our study. We cannot account for lactation in subsequent pregnancies. However, breast feeding following the current pregnancy did not predict breast cancer in this sample and was not a confounder of PCB associations. There was no correlation between breast feeding following the observed pregnancy and PCB 203, 187 , or 167 . These findings may be explained by the low frequency of long-term breast feeding in our cohort. Rates of lactation in this sample were low (34\%) and among those who did breast feed, most $(60 \%)$ breast fed for
$<4$ months [25]. We suggest that it is unlikely that lactation in subsequent pregnancies explains our results, as lactation behavior is highly correlated among pregnancies [30], but this remains a possibility.

The variable distribution of PCB congeners observed in study subjects is to be expected as the distribution of congeners depends on source of exposure which is influenced by the chemical structure of each congener. Exposure also depends on the fate of the congener in the ecosystem which ultimately forms the source of human exposure and on the individual response to the exposure. All these factors contribute differently to the measured serum level [31]. In a previous report on in utero PCB exposure and daughter's time to pregnancy, we also found considerable variability in the mixture of $\mathrm{PCB}$ congeners in CHDS mothers [26]. In the US, total PCB levels in adipose tissue declined steadily after 1972 when restrictions were implemented. A decline in PCBs was also observed in archived blood samples in Norway during the same period [32] and in human adipose tissue in the United States [33]. However, secular trends in the mix of congeners are unknown [33]. As the fate of individual congeners in the environment depends on their structure, environmental topography, and climate, and because individual characteristics may determine routes of exposure, and metabolic fate, it is unlikely that trends for individual congeners are the same over time, or within individuals, or across geographic areas [14]. There is little human data on this topic, but results of repeated blood sampling in a Danish cohort provides limited support for the concept that congener proportions vary over time: over a 5-year period (1976-1978 vs. 1981-1983) median concentration of total PCBs declined $11 \%$, but median concentration of PCB 118 declined $34 \%$, PCB 180 declined $4 \%$, and PCB 153 declined $9 \%$.(adapted from Hoyer, et al., Table 1, p. 179) [34]. If congener mixture is the underlying risk factor, then we might expect different results for epidemiological studies, depending on place, time, age, and other individual characteristics that might alter external and internal dose to these compounds.

Given the variability of congener mixtures observed in our cohort, we speculate that an underlying host factor related to metabolism of these compounds might contribute to the PCB associations with breast cancer that we have observed in this study. These data do not allow us to determine whether PCB exposure would be necessary to trigger an effect, or whether some host factor might be sufficient to increase breast cancer risk. Our analysis does indicate that PCB associations observed in this study are independent of DDT associations previously observed in this cohort [25]. Mechanistic studies in experimental models, or in vitro are likely to be very important to explaining the associations we report here, and for 
explaining the human breast cancer associations previously reported for CYP1A1 polymorphisms in relation to $\mathrm{PCB}$ exposure in middle-aged women [10-13].

In summary, in this study, the mixture of PCB congeners predicted the estimated effect of PCB exposure on risk of breast cancer. Overall, women in this study showed a variable distribution for the three PCB congeners that predicted breast cancer. Women with a high proportion of PCB 203 (top $25 \%$ of the study population) relative to PCBs 167 and 187 had a nearly threefold increase in subsequent risk of breast cancer, compared to women with a lower proportion of PCB 203 (bottom $25 \%$ of the study population). The relation of PCB exposure to breast cancer might be clarified by additional laboratory, experimental and human population studies that account for timing of exposure in relation to windows of susceptibility for the breast and for concomitant host factors. It is likely to be particularly important to study congener mixtures and individual response to multiple exposures. It remains unclear whether individual differences in exposure, response to exposure, or both explain risk patterns observed.

Acknowledgments This publication was made possible by the Breast Cancer and the Environment Research Program (BCERP) award number (U01 ES/CA 019471 to B.A.C. and M.B.T.), from the National Institute of Environmental Health Sciences (NIEHS) and the National Cancer Institute (NCI), NIH, DHHS; the National Cancer Institute award number (R01 CA72919 to B.A.C); and The National Institute of Child Health and Human Development award numbers (N01 HD 63258 and N01 HD 13334 to B.A.C.). Its contents are solely the responsibility of the authors and do not necessarily represent the official views of the NIEHS or NCI, NICHD or the National Institutes of Health. We also gratefully acknowledge support of the Avon Foundation for this research, and our collaborators Mary Wolff who performed serum assays for this study, Robert Sholtz and Nikilou Krigbaum who prepared data files, Linda S. Birnbaum who provided comments on an earlier version of this manuscript, Barbara J. van den Berg, Roberta Christianson the late Frank Oechsli and the late Jacob Yerushalmy, Child Health and Development Studies founder, who together created and preserved the Child Health and Development Studies cohort. We also thank the National Institute of Child Health and Human Development, both current and past directors, Alan Guttmacher and Dwayne Alexander, and our project officer, Gilman Grave for supporting the maintenance of the CHDS cohort. The collection of cancer incidence data used in this study was supported by the California Department of Public Health as part of the statewide cancer reporting program mandated by California Health and Safety Code Section 103885; the National Cancer Institute's Surveillance, Epidemiology and End Results Program under contract N01-PC35136 awarded to the Northern California Cancer Center, contract N01-PC35139 awarded to the University of Southern California, and contract N02-PC-15105 awarded to the Public Health Institute; and the Centers for Disease Control and Prevention's National Program of Cancer Registries, under agreement \#U55/CCR921930-02 awarded to the Public Health Institute. The ideas and opinions expressed here in are those of the author(s) and endorsement by the State of California, Department of Public Health, the National Cancer Institute, and the Centers for Disease Control and Prevention or their contractors and subcontractors is not intended nor should be inferred.

Conflict of interest The authors declare that they have no conflict of interest.
Open Access This article is distributed under the terms of the Creative Commons Attribution Noncommercial License which permits any noncommercial use, distribution, and reproduction in any medium, provided the original author(s) and the source are credited.

\section{References}

1. Fenton SE (2006) Endocrine-disrupting compounds and mammary gland development: early exposure and later life consequences. Endocrinology 147(6):s18-s24

2. Rudel RA, Fenton SE, Ackerman JM, Euling SY, Makris SL (2011) Environmental exposures and mammary gland development: state of the science, public health implications, and research recommendations. Environ Health Perspect 119(8):1053-1061

3. Wang T, Gavin HM, Arlt VM, Lawrence BP, Fenton SE, Medina D, Vorderstrasse BA (2011) Aryl hydrocarbon receptor activation during pregnancy, and in adult nulliparous mice, delays the subsequent development of DMBA-induced mammary tumors. Int J Cancer 128(7):1509-1523

4. Azim HA Jr, Santoro L, Russell-Edu W, Pentheroudakis G, Pavlidis N, Peccatori FA (2012) Prognosis of pregnancy-associated breast cancer: a meta-analysis of 30 studies. Cancer Treat Rev 38(7):834-842

5. Birnbaum LS, Fenton SE (2003) Cancer and developmental exposure to endocrine disruptors. Environ Health Perspect 111(4): 389-394

6. Moysich KB, Menezes RJ, Baker JA, Falkner KL (2002) Environmental exposure to polychlorinated biphenyls and breast cancer risk. Rev Environ Health 17(4):263-277

7. Negri E, Bosetti C, Fattore E, La Vecchia C (2003) Environmental exposure to polychlorinated biphenyls (PCBs) and breast cancer: a systematic review of the epidemiological evidence. Eur J Cancer Prev 12(6):509-516

8. Brody JG, Moysich KB, Humblet O, Attfield KR, Beehler GP, Rudel RA (2007) Environmental pollutants and breast cancer: epidemiologic studies. Cancer 109(12 Suppl):2667-2711

9. Cohn BA (2011) Developmental and environmental origins of breast cancer: DDT as a case study. Reprod Toxicol 31(3): 302-311

10. Moysich KB, Shields PG, Freudenheim JL, Schisterman EF, Vena JE, Kostyniak P, Greizerstain H, Marshall JR, Graham S, Ambrosone CB (1999) Polychlorinated biphenyls, cytochrome P4501A1 polymorphisms, and postmenopausal breast cancer risk. Cancer Epidemiol Biomark Prev 8:41-44

11. Laden F, Ishibe N, Hankinson SE, Wolff MS, Gertig DM, Hunter DJ, Kelsey KT (2002) Polychlorinated biphenyls, cytochrome P450 1A1, and breast cancer risk in the nurses' health study. Cancer Epidemiol Biomark Prev 11(12):1560-1565

12. Zhang Y, Wise JP, Holford TR, Xie H, Boyle P, Zahm SH, Rusiecki J, Zou K, Zhang B, Zhu Y, Owens PH, Zheng T (2004) Serum polychlorinated biphenyls, cytochrome P-450 1A1 polymorphisms, and risk of breast cancer in Connecticut women. Am J Epidemiol 160(12):1177-1183

13. Li Y, Millikan RC, Bell DA, Cui L, Tse CK, Newman B, Conway K (2005) Polychlorinated biphenyls, cytochrome P450 1A1 (CYP1A1) polymorphisms, and breast cancer risk among African American women and white women in North Carolina: a population-based case-control study. Breast Cancer Res 7(1):R12R18

14. Erickson MD (2001) PCB properties, uses, occurence, and regulatory history. In: Robertson LW, Hansen LG (eds) PCBs recent advances in environmental toxicology and health effects. The University Press of Kentucky, Lexington, pp xi-xxx 
15. Longnecker MP, Klebanoff MA, Gladen BC, Berendes HW (1999) Serial levels of serum organochlorines during pregnancy and postpartum. Arch Environ Health 54(2):110-114

16. van den Berg BJ, Christianson RE, Oechsli FW (1988) The California Child Health and Development Studies of the School of Public Health, University of California at Berkeley. Paediatr Perinat Epidemiol 2(3):265-282

17. Cohn BA, Cirillo PM, Christianson RE, van den Berg BJ, Siiteri PK (2001) Placental characteristics and reduced risk of maternal breast cancer. J Natl Cancer Inst 93(15):1133-1140

18. Kwong SL, Perkins CI, Morris CR, Cohen R, Allen M, Wright WE (2001) Cancer in California: 1988-1999. California Department of Health Services, Cancer Surveillance Section, Sacramento, CA

19. Gammon MD, Wolff MS, Neugut AI, Eng SM, Teitelbaum SL, Britton JA, Terry MB, Levin B, Stellman SD, Kabat GC, Hatch M, Senie R, Berkowitz G, Bradlow HL, Garbowski G, Maffeo C, Montalvan P, Kemeny M, Citron M, Schnabel F, Schuss A, Hajdu S, Vinceguerra V, Niguidula N, Ireland K, Santella RM (2002) Environmental toxins and breast cancer on Long Island. II. Organochlorine compound levels in blood. Cancer Epidemiol Biomarkers Prev 11(8):686-697

20. Brock JW, Burse VW, Ashley DL, Najam AR, Green VE, Korver MP, Powell MK, Hodge CC, Needham LL (1996) An improved analysis for chlorinated pesticides and polychlorinated biphenyls (PCBs) in human and bovine sera using solid-phase extraction. J Anal Toxicol 20(7):528-536

21. Long GL, Winefordner JD (1983) Limit of detection. A closer look at the IUPAC definition. Anal Chem 55(7):712A-724A

22. Taylor J (1987) Quality assurance of chemical measurements. Lewis Publishers, Inc., Chelsea, pp 125-126

23. Berkowitz GS, Obel J, Deych E, Lapinski R, Godbold J, Liu Z, Landrigan PJ, Wolff MS (2003) Exposure to indoor pesticides during pregnancy in a multiethnic, urban cohort. Environ Health Perspect 111(1):79-84

24. Wolff MS, Camman D, Gammon M, Stellman SD (1997) Proposed PCB congener groupings for epidemiological studies. Environ Health Perspect 105(1):13-14

25. Cohn BA, Wolff MS, Cirillo PM, Sholtz RI (2007) DDT and breast cancer in young women: new data on the significance of age at exposure. Environ Health Perspect 115(10):1406-1414

26. Cohn BA, Cirillo PM, Sholtz RI, Ferrara A, Park JS, Schwingl PJ (2011) Polychlorinated biphenyl (PCB) exposure in mothers and time to pregnancy in daughters. Reprod Toxicol 31(3):290-296

27. Yang XR, Chang-Claude J, Goode EL, Couch FJ, Nevanlinna H, Milne RL, Gaudet M, Schmidt MK, Broeks A, Cox A, Fasching PA, Hein R, Spurdle AB, Blows F, Driver K, Flesch-Janys D, Heinz J, Sinn P, Vrieling A, Heikkinen T, Aittomäki K, Heikkilä P, Blomqvist C, Lissowska J, Peplonska B, Chanock S, Figueroa J, Brinton L, Hall P, Czene K, Humphreys K, Darabi H, Liu J, Van' t Veer LJ, van Leeuwen FE, Andrulis IL, Glendon G, Knight JA, Mulligan AM, O'Malley FP, Weerasooriya N, John EM, Beckmann MW, Hartmann A, Weihbrecht SB, Wachter DL, Jud SM, Loehberg CR, Baglietto L, English DR, Giles GG,
McLean CA, Severi G, Lambrechts D, Vandorpe T, Weltens C, Paridaens R, Smeets A, Neven P, Wildiers H, Wang X, Olson JE, Cafourek V, Fredericksen Z, Kosel M, Vachon C, Cramp HE, Connley D, Cross SS, Balasubramanian SP, Reed MWR, Dörk T, Bremer M, Meyer A, Karstens JH, Ay A, Park-Simon T-W, Hillemanns P, Arias Pérez JI, Rodríguez PM, Zamora P, Benítez J, Ko Y-D, Fischer H-P, Hamann U, Pesch B, Brüning T, Justenhoven C, Brauch H, Eccles DM, Tapper WJ, Gerty SM, Sawyer EJ, Tomlinson IP, Jones A, Kerin M, Miller N, McInerney N, Anton-Culver H, Ziogas A, Shen C-Y, Hsiung C-N, Wu P-E, Yang S-L, Yu J-C, Chen S-T, Hsu G-C, Haiman CA, Henderson BE, Le Marchand L, Kolonel LN, Lindblom A, Margolin S, Jakubowska A, Lubiński J, Huzarski T, Byrski T, Górski B, Gronwald J, Hooning MJ, Hollestelle A, van den Ouweland AMW, Jager A, Kriege M, Tilanus-Linthorst MMA, Collée M, Wang-Gohrke S, Pylkäs K, Jukkola-Vuorinen A, Mononen K, Grip M, Hirvikoski P, Winqvist R, Mannermaa A, Kosma V-M, Kauppinen J, Kataja V, Auvinen P, Soini Y, Sironen R, Bojesen SE, Dynnes Ørsted D, Kaur-Knudsen D, Flyger H, Nordestgaard BG, Holland H, Chenevix-Trench G, Manoukian S, Barile M, Radice P, Hankinson SE, Hunter DJ, Tamimi R, Sangrajrang S, Brennan P, McKay J, Odefrey F, Gaborieau V, Devilee P, Huijts PEA, Tollenaar R, Seynaeve C, Dite GS, Apicella C, Hopper JL, Hammet F, Tsimiklis H, Smith LD, Southey MC, Humphreys MK, Easton D, Pharoah P, Sherman ME, Garcia-Closas M (2011) Associations of breast cancer risk factors with tumor subtypes: a pooled analysis from the Breast Cancer Association Consortium Studies. J Natl Cancer Inst 103(3):250-263

28. Azim HA Jr, Michiels S, Bedard PL, Singhal SK, Criscitiello C, Ignatiadis M, Haibe-Kains B, Piccart MJ, Sotiriou C, Loi S (2012) Elucidating prognosis and biology of breast cancer arising in young women using gene expression profiling. Clin Cancer Res 18(5):1341-1351

29. Agency for Toxic Substances and Disease Registry (2000) Toxicological profile for polychlorinated biphenyls (PCBs). US Department of Health and Human Services, Public Health Service, Atlanta

30. Phillips G, Brett K, Mendola P (2011) Previous breastfeeding practices and duration of exclusive breastfeeding in the United States. Matern Child Health J 15(8):1210-1216

31. Beyer A, Biziuk M (2009) Environmental fate and global distribution of polychlorinated biphenyls. Rev Environ Contam Toxicol 201:137-158

32. Ward E, Schulte P, Grajewski B, Andersen A, Patterson DJ, Turner W, Jellum E, Deddens J, Friedland J, Roeleveld N, Waters M, Butler M, DiPietro E, Needham L (2000) Serum organochlorine levels and breast cancer: a nested case-control study of Norwegian women. Cancer Epidemiol Biomarkers Prev 9(12):1357-1367

33. Kutz FW, Wood PH, Bottimore DP (1991) Organochlorine pesticides and polychlorinated biphenyls in human adipose tissue. Rev Environ Contam Toxicol 120:1-82

34. Hoyer AP, Torben J, Grandjean P, Helle BH (2000) Repeated measurements of organochlorine exposures and breast cancer risk (Denmark). Cancer Causes Control 11(2):177-184 